\title{
Detección de leishmania en tejido medular de murciélagos y roedores de zona endémica a leishmaniasis canina en Corrientes, Argentina
}

\author{
Ruiz, R.M.; Alegre, E.A.; Ramirez, G.V. \\ Cátedra Salud Pública. Fac. Cs. Veterinarias, Univ. Nac. del Nordeste (UNNE). \\ Sargento Cabral 2139, Corrientes (3400), Argentina. \\ Raquel_monicaruiz@hotmail.com
}

\begin{abstract}
Resumen
Ruiz, R.M.; Alegre, E.A.; Ramirez, G.V. Detección de leishmania en tejido medular de murciélagos y roedores de zona endémica a leishmaniasis canina en Corrientes, Argentina. Rev. Vet. 32: 1, 31-36, 2021. La problemática de la leishmaniasis en América radica en sus complejos y variantes aspectos epidemiológicos de presentación. Si bien en la ciudad de Corrientes, los caninos domésticos representan el principal reservorio urbano, no se conoce la participación de otros mamíferos en el ciclo de transmisión urbana, sin embargo ya fue propuesta para otras especies animales en distintas áreas urbanas a nivel mundial. En base a trabajos previos y conocimiento sobre la alta población de roedores y murciélagos que habitan en esta ciudad, en estrecho contacto con el hombre, nos planteamos como objetivo general conocer la posible participación de estas especies animales en la cadena epidemiológica, detectando si existe una infección natural activa, su prevalencia e identificación de especies circulantes, aplicando técnicas de detección por biología molecular. Se trabajó con muestras de médula ósea, por ser un tejido con el principal patrón de distribución de Leishmania visceral. Se realizaron capturas de ambas especies animales en coincidencia con zonas identificadas con alta prevalencia de leishmaniasis canina. De 90 capturas se obtuvieron 82 muestras (50 murciélagos y 32 roedores), las que fueron sometidas a una Nested PCR genérica para Leishmania sp. Aquéllas que resultaron detectables fueron sometidas a dos PCR simples, específicas para identificar especies de Leihmania (V) braziliensis y L. (L) chagasi. Como resultado se obtuvo una alta prevalencia $(21,8 \%)$ en muestras de roedores con la probabilidad de asumir el papel de reservorios, mientras que para los murciélagos, si bien se detectó la infección natural, la prevalencia hallada de $10 \%$ no fue suficiente para considerar a esta especie como posible reservorio, pero sí posibles huéspedes putativos en situaciones eco-epidemiológicas especiales o diseminadores de la parasitosis.
\end{abstract}

Palabras clave: murciélagos, ratas, Leishmania sp, medula ósea, PCR.

\begin{abstract}
Ruiz, RM; Alegre, EA; Ramirez, GV. Detection of Leishmania in medullary tissue of bats and rodents that inhabit an endemic area for canine leishmaniasis in Corrientes, Argentina. Rev. Vet. 32: 1, 31-36, 2021. The problem of leishmaniasis in America lies in its complex and varied epidemiological aspects of presentation. Although in the City of Corrientes, domestic canines represent the main urban reservoir, the participation of other mammals in the urban transmission cycle is not known, however, it has already been proposed for other animal species in different urban areas worldwide. Based on previous work and knowledge about the high population of rodents and bats know the possible participation of these animal species in the epidemiological chain, detecting whether there is an active natural infection, its prevalence and identification of circulating species, applying detection techniques by molecular biology. Bone marrow samples were used, as it is a tissue with the main distribution pattern of visceral Leishmania. Captures of both animal species were made in coincidence with areas of the city of Corrientes identified with high prevalence for canine leishmaniasis. From 90 captures, 82 samples were obtained (50 bats and 32 rodents) which were subjected to a generic Nested PCR for Leishmania sp, and those that were detectable, were subjected to two specific simple PCRs to identify Leihmania (V) braziliensis and $L$. (L) chagasi species. As a result, a high prevalence of $21.8 \%$ was obtained in rodent samples with the probability of playing the role of reservoirs, while for bats, although natural infection was detected, the prevalence found of $10 \%$ was not sufficient to consider this species as
\end{abstract}


a possible reservoir, but possible putative hosts in special eco-epidemiological situations or disseminators of parasitosis.

Key words: bats, rats, Leishmania $s p$, bone marrow, PCR.that inhabit the City of Corrientes in close contact with man, our general objective is to

\section{INTRODUCCIÓN}

La leishmaniasis es una enfermedad que afecta al hombre y a numerosas especies de mamíferos, de presentación variable según la interrelación de numerosos factores inherentes al huésped, al parásito y al medio ambiente ${ }^{16}$.

La problemática de la leishmaniasis en América radica en sus complejos y variantes aspectos epidemiológicos de presentación. La identificación de huéspedes naturales de Leishmania y reservorios, es de fundamental importancia para comprender el ciclo natural del parásito y la epidemiología de la enfermedad en un área determinada, remarcando de esta manera la necesidad de estudios de focos activos ${ }^{17}$.

Si bien los caninos son epidemiológicamente importantes como reservorios urbanos en diferentes regiones de América, sobre todo para L. infantum chagasi ${ }^{22}$, la idea de que sean los único reservorios ha llevado a las autoridades de salud, en muchas ocasiones, al sacrifico de estos animales como única medida de control de la zoonosis, con baja efectividad en los resultados de tales programas al no tener en cuenta un análisis de múltiples variables influyentes ${ }^{5}$.

Por otro lado, la participación en el ciclo de transmisión de $L$. infantum de otros mamíferos infectados en zonas urbanas diferentes a caninos domésticos, ya fue propuesta para otras especies animales como gatos ${ }^{20}$ y zarigüeyas de hábitat urbano y peri-urbano ${ }^{4}$, por lo que la participación putativa de otros mamíferos debería ser considerada en las propuestas de control de esta zoonosis, no solo por su identificación como reservorios, sino también como estrategias de conservación de sus nichos ecológicos.

Existen suficientes antecedentes sobre el rol que juegan los roedores en la manutención de ciclos de Leishmnia en diferentes zonas geográficas, reportados en varias especies de roedores silvestres y sinantrópi$\cos ^{8}$. También se investigaron en zona endémica, diferentes especies de murciélagos y su rol como huéspedes de infección natural ${ }^{3} \mathrm{o}$ su papel como reservorios ${ }^{15} \mathrm{en}$ zonas endémicas ${ }^{3} \mathrm{y}$ no endémicas a leishmaniasis ${ }^{11}$.

Corrientes y Misiones son provincias consideradas de mayor importancia en la prevalencia de leishmaniasis en el hombre y también en otros animales. Tal situación epidemiológica ha marcado a la Provincia de Corrientes como endémica ${ }^{12}$, pero poco se sabe sobre la verdadera eco-epidemiología de este lugar y la participación de otras especies animales, fuera de los caninos, como posibles intervinientes en la manutención de la enfermedad en el tiempo y en un biotopo determinado.
En base a trabajos previos del equipo de investigación y con el conocimiento sobre roedores y murciélagos de la Ciudad de Corrientes en estrecha convivencia con el hombre, nos planteamos nuestro objetivo de estudio, basado en conocer la posible participación de estas especies animales en el ciclo de la parasitosis, manteniendo el agente etiológico como huéspedes naturales, reservorios, huéspedes putativos o diseminadores.

Se planteó detectar la infección natural y determinar su prevalencia en la Ciudad de Corrientes con métodos de alta sensibilidad como las técnicas de biología molecular, de elección en estudios epidemiológicos en animales silvestres ${ }^{23}$.

En este estudio se trabajó particularmente con muestras de médula ósea de tales pequeños mamíferos, por ser un tejido en el cual se presenta el principal patrón de distribución de Leishmania visceral, para detectar la presencia de $\mathrm{ADN}$ del parásito, como así también la identificación de especies de leishmanias.

\section{MATERIAL Y MÉTODOS}

El estudio se realizó durante el período 2018-2019, en zona urbana de la Ciudad de Corrientes, Argentina ( $\left.27^{\circ} 28^{\prime} 50^{\prime \prime} \mathrm{S}, 58^{\circ} 50^{\prime} 02^{\prime \prime} \mathrm{E}\right)$. Los puntos de muestreo fueron equivalentes a focos y barrios con prevalencia a leishmaniasis canina (visceral / cutánea), teniendo en cuenta registros de la Dirección de Zoonosis de la Municipalidad de la Ciudad de Corrientes, a los que se sumaron datos de consultorios privados.

El presente trabajo es parte de un proyecto mayor acreditado por la Sec. Gral de CyT UNNE), aprobado por el Comité de Ética y Bioseguridad de la Facultad de Ciencias Veterinarias de la UNNE (expediente 142019-02029, protocolo $\mathrm{N}^{\circ}$ 0084)

Para la captura de roedores se utilizaron jaulas tipo Sherman que fueron colocadas en áreas de mayor prevalencia de casos de leishmaniasis canina. Las jaulas se ubicaron de forma intra y peri-domiciliaria, dos noches seguidas por cada lugar identificado.

Los roedores capturados fueron trasladados al laboratorio de la cátedra de Salud Pública de la Facultad de Ciencias Veterinarias de la UNNE, para ser identificados según clave de Osgood (1943) y registrados por edad, sexo y datos clínicos sobre identificación de alopecias, áreas escamosas y lesiones en punta de orejas, hocico, cola, base de la cola y pulpejos de los cuatro miembros.

Para la captura de quirópteros, se identificaron los refugios por medio de métodos auditivos, avistamientos e identificación de rastros. La captura se realizó de acuerdo al lugar y tipo de refugio, utilizando redes de 
niebla, captura directa en forma manual o "trampa balde". El manejo y traslado se realizó en bolsas de tela de paño hasta el laboratorio, donde los murciélagos fueron identificados según clave de Bárquez y Díaz ${ }^{1}$ y se registraron sus datos al igual que los descriptos para roedores.

Para obtener las muestras de ambas especies se realizó la eutanasia de los animales con pentobarbital sódico (Euthanyle) vía intraperitoneal, previa sedación con una combinación de Ketamina/Acepromacina. Luego se realizó la disección de los animales exponiendo los huesos largos -húmero y fémur- para ser seccionados en forma transversal y exponer el orificio medular (Figura 1), a través del cual se introdujo una aguja con jeringa de tuberculina heparinizada realizando de esta manera la extracción del tejido medular (Figura 2), para ser colocado en Eppendorf libres de ADN.

Para la extracción del ácido desoxirribonucleico $(\mathrm{ADN})$ se realizó una digestión con detergente $\mathrm{CTAB}$ (bromuro de cetil trimetilamonio) y purificación con cloroformo: alcohol isoamílico. Se aplicó una técnica de PCR para control de material genético extraído de quirópteros ${ }^{14} \mathrm{y}$ otra técnica para las ratas ${ }^{30}$.

Como marcador de peso molecular se utilizó pGEM ${ }^{\circledR}$ DNA (Promega) para murciélagos y Cienmarker (Biodynamics) para ratas. Para ambas PCR se utilizó agua destilada como control negativo. Los productos de PCR se separaron por electroforesis en geles de agarosa al $1 \%$ y $2 \%$ respectivamente en buffer TBEIX, teñidos con bromuro de etidio y visualizados por transiluminación UV.

Para la identificación de leishmanias se aplicó una nested PCR para detectar ADN de protozoos del género Leishmania $s p$. En la primera ronda se utilizaron primers que amplifican bandas de $520 \mathrm{pb}^{29} \mathrm{y}$ con el producto de amplificación de esta primera PCR se aplicó la segunda ronda con iniciadores que amplificaron bandas de $490 \mathrm{pb}^{25}$.

Los productos de PCR fueron revelados por electroforesis horizontales con buffer TBE1X en geles de agarosa al $2 \%$ teñido con bromuro de etidio y visualizados por transiluminación UV, utilizando como marcador de peso molecular Cienmarker (Biodynamics).

Para la Identificación de especies de Leishmania (V) braziliensis y L. (L) chagasi se trabajó con muestras que resultaron positivas a la nested $\mathrm{PCR}$, aplicando PCR sencillas bajo condiciones que ya fueron descriptas para ambas especies $L$. (L) chagasi y Leishmania (V) braziliensis ${ }^{6}$.

Como control positivo para las tres técnicas (genérica y dos sencillas), se utilizó ADN de Leishmania sp, Leishmanias chagasi y braziliensis provenientes del Instituto Nacional de Parasitología "Dr. Mario Fatala Chaben", Argentina, además de agua destilada como control negativo. Los productos de PCR fueron revelados por electroforesis horizontales en geles de agarosa en buffer TBE (Tris- Acido bórico- EDTA) 1X, teñidos con bromuro de etidio y visualizados por transiluminación UV.
Se utilizó un marcador de peso molecular Cienmarker (Biodynamics) para la comparación de tamaños de los fragmentos amplificados. Se determinó la prevalencia genérica específica de esta parasitosis y la prevalencia diferencial entre especies de Leishmania $s p p$ en las diferentes especies animales que conviven en una zona urbana y endémica.

\section{RESULTADOS}

Se capturaron 90 animales para su muestreo, 40 roedores y 50 quirópteros. Los roedores capturados fueron identificados en su totalidad pertenecientes al género Rattus rattus. El 80\% de las capturas ocurrieron dentro del domicilio, el resto fue peri-domiciliario, y solamente 3 capturas se lograron en áreas abiertas. Todos los roedores fueron clasificados como adultos, 12 hembras y el resto machos. A la inspección clínica no se detectaron signos o características visibles compatibles con leishmaniasis.

Ocho animales del total de capturados no fueron muestreados, por encontrarse en estado de preñez, o por no lograr obtener suficiente tejido medular para la repetición de cada una de las 5 PCR por muestra (control de especie, anidada y para especie braziliensis y chagasi).

Por lo tanto se procesaron 32 muestras de ADN y se logró detectar por medio de la técnica Nested $\mathrm{PCR}$ para el género Leishmania, primer round, la amplificación de bandas de $520 \mathrm{pb}$ en 9 muestras, al aplicar al producto de esta primer PCR una segunda vuelta para incrementar la sensibilidad del diagnóstico, la amplificación de bandas de $490 \mathrm{pb}$ se detectó en 7 de las 9 muestras positivas al ADN del género Leishmania por lo cual la prevalencia hallada fue del $21,8 \%$.

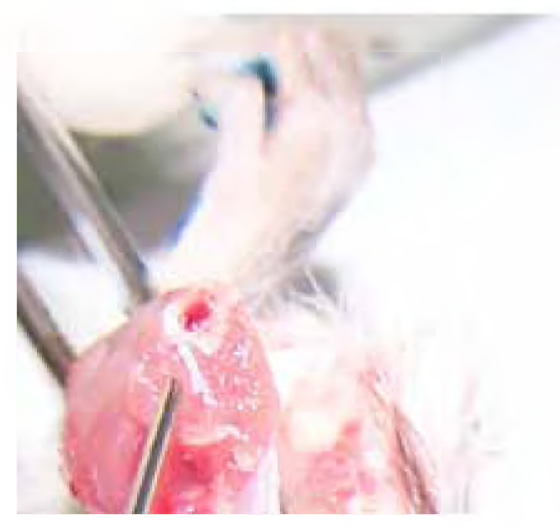

Figura 1. Apertura de hueso largo y vista del canal medular.

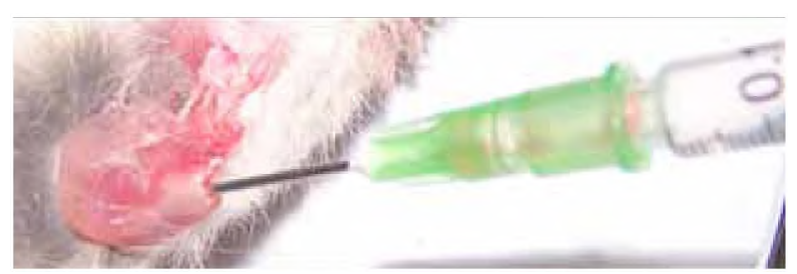

Figura 2. Absorción de tejido medular a través de jeringa de tuberculina heparinizada. 
De las muestras positivas obtuvimos la identificación de la especie L. chagasi para 5 muestras, una para Leishmania braziliensis y una muestra no detectable para ninguna de las dos especies analizadas.

En cuanto a los murciélagos, se logró la captura de 50 animales. Tres fueron capturados con red de niebla, otros tres en huecos de árboles con trampa balde y los 44 restantes se capturaron con el método manual y trampa balde en refugios artificiales de viviendas habitadas por el hombre. A la inspección clínica no presentaron lesiones compatibles con leishmaniasis.

Se identificaron 37 machos (30 adultos +7 juveniles) y 13 hembras adultas. Se logró identificar a los murciélagos incluidos en dos de las 4 familias que habitan en la Provincia de Corrientes, las familias Mollosidae y Vespertillonidae, insectívoras.

Se procesaron 50 muestras con la aplicación de la técnica nested PCR, para ambas rondas, se logró detectar bandas de amplificación de $520 \mathrm{pb}$ y $490 \mathrm{pb}$ en 5 muestras, 3 para la especie Eumops patagonicus y 2 para la especie Myotis albescens.

Cuatro muestras de las totales resultaron positivas para $L$ chagasi (dos para Eumops patagonicus y dos para Myotis albescens) y una resultó no detectable para ambas especies de Leishmanias en murciélago Eumops patagonicus.

\section{DISCUSIÓN}

Con respecto a los roedores, el alto porcentaje de capturas intra-domiciliarias, probablemente se deba a la especie dominante en la zona urbana de la Ciudad de Corrientes, y el sexo y la edad predominante respondan a las características de comportamiento territorial y curioso de estos animales ${ }^{10}$

En cuanto a Leishmania, se detectó una alta prevalencia que supera la establecida para considerar a Rattus rattus como probable reservorio urbano ${ }^{9}$, característica ya descripta por otros autores en Rattus rattus que habitan Venezuela ${ }^{8}$, como también la misma especie y Rattus. norvegicus en Colombia ${ }^{28}$

En México también se constató en áreas urbanas la infección natural a Leishmania en $R$. rattus, $R$. norvegicus y $M$. musculus ${ }^{21}$; y en Brasil, al igual que en nuestro trabajo, se reportó la infección natural en tejido medular de hueso femoral de Mus musculus ${ }^{28}$. No solo en América se obtuvieron resultados sobre la detección de roedores sinantrópicos como huéspedes naturales, también en Turquía ocurrió en la especie $R$ rattus ${ }^{27}$. En Irán y zonas geográficas circundantes a ésta, se corroboró en las especies M. musculus y $R$. norvegicus ${ }^{19}$.

Basándonos en numeroso trabajos científicos a nivel mundial, podríamos afirmar que los roedores cumplen distintos roles según área geográfica, ya sea como huéspedes naturales, importantes diseminadores o en algunos casos, como uno de los principales reservorios $^{7}$.

En cuanto a los quirópteros, la captura más eficiente que obtuvimos se relacionó a los numerosos refugios en estructuras edilicias en zona urbana de la ciudad de Corrientes, en estrecho contacto con el hombre. La edad y sexo del mayor porcentaje capturado también responde a conductas comportamentales propias de la especie.

En cuanto a la detección de Leishmania se halló una baja prevalencia, con un valor que no representa la posibilidad de constituir una especie que se comporte como verdadero reservorio, al menos, en este escenario epidemiológico y con las características de este estudio, no dejando de lado la posibilidad de un rol en la dinámica de la transmisión como reservorios secundarios o esparcidores endémicos que suplanten o ayuden al reservorio primario de la zona geográfica a mantener el agente etiológico en la región.

La baja prevalencia hallada concuerda con resultados obtenidos en la ciudad de México ${ }^{3}$, sin embargo en murciélagos que habitan Brasil, se ha detectado una prevalencia marcadamente alta de $40 \%$, por lo cual se adjudica a estos mamíferos el papel de perfectos reservorios de la zona estudiada ${ }^{26}$. Estos hallazgos remarcan la problemática que presenta la leishmaniasis en cuanto a su marcado dinamismo, dado por alteraciones en el medio ambiente, reservorios, vectores y cambios demográficos realizados por el hombre ${ }^{18}$.

En referencia a las especies del parásito, en ambos animales el mayor porcentaje se atribuye a Leishmania infantum (chagasi), resultados que podrían ser esperados en base a la clase de tejido estudiado y al conocimiento de patrones de distribución del parásito dependientes de la especie de Leishmania. Sin embargo, se ha demostrado que a pesar de existir patrones de distribución, en algunos casos pueden existir focos crípticos en sitios no comunes como fue demostrado con L. trópica, claramente dermatotrópica, pero con asiento también en otros lugares como hueso, médula y epididímo ${ }^{7}$.

En poblaciones de la India se ha demostrado que la Leishmania trópica aparte de asentarse en piel también lo hace de formas importante en médula ósea, constituyendo una leishmaniasis visceral ${ }^{13}$. En nuestros resultados no se detectó $L$. braziliensis en murciélagos pero sí pudimos hacerlo en tejido medular de rata, especie claramente identificada como dermatotrópica, pero no es desacertada o imposible esta ubicación, debido a que otras especies también con patrón cutáneo, como L. mexicana amazonensis, fueron identificadas en tejido medular y causantes de leishmaniasis visceral en el hombre ${ }^{2}$.

Al contrario, también existen trabajos donde se detectaron especies de Leishmania de tipo cutánea en el hombre, con marcado asentamiento en las vísceras de roedores, lo cual refuerza la idea de que el tropismo no es el mismo en diferentes especies ${ }^{24}$. Es importante destacar que los patrones de distribución no solo dependen de la especie del parásito, sino también de la célula huésped y del estado general que esté presente, pudiendo aquellas Leishmanias que normalmente poseen presentación cutánea, por alguna situación, visceralizarse ${ }^{13,26}$ 
En nuestro caso, también hallamos muestras de tejido medular de ratas y murciélagos que siendo positivas al género Leishmania, resultaron negativas a las dos especies testeadas, lo cual demuestra la posibilidad que otra especie se encuentre circulando en nuestra región y que posea asiento en médula de pequeños mamiferos, que claramente se presenta con baja densidad.

En base a los resultados obtenidos y el análisis bibliográfico de otras regiones, concluimos que existe alta posibilidad de que otros mamífero, fuera de los caninos considerados los principales reservorios urbanos en la Ciudad de Corrientes, colaboren en mantener ciclos de la enfermedad para que el agente etiológico se perpetué en esta zona geográfica a través del tiempo, reforzando el nuevo concepto de reservorio, que remarca la necesidad de una red de hospedadores y características ambientales necesarias para presentar el mejor escenario de mantenimiento.

Si bien más estudios serán necesarios para darle continuidad al conocimiento sobre patrones de distribución de Leishmanias en pequeños mamíferos y su implicancia epidemiológica, los presentes resultados colaboran con la vigilancia activa que debe realizarse en diferentes especies animales involucradas en un ecosistema determinado, sumando criterios para la interpretación de un enfoque ecológico integrado.

Estos resultados, junto a otros pocos estudios en Argentina, constituyen actualmente las primeras piezas de evidencia del papel que murciélagos y roedores desempeñan en el ciclo de la enfermedad en una zona urbana.

\section{REFERENCIAS}

1. Bárquez, RM, Díaz MM. 2020. Nueva Guia de Murciélagos de Argentina, publicación especial N³ PCMA, Tucumán, Argentina, $186 \mathrm{p}$.

2. Barral A et al. 1986. Isolation of Leishmania Mexicana Amazonensis from the bone marrow in a case of american visceral leishmaniasis. The Am J Trop Med and Hygien 35: 732-734.

3. Berzunza CM et al. 2015. Leishmania mexicana infected bats in Mexico: Novel potential reservoirs. PLoSNegl Trop Dis 9: 1-15.

4. Bodini ME et al. 2007. An investigation of Leishmania sp in Didelphis $s p$ from urban and peri-urban areas in Bauru (São Paulo, Brazil). Vet Parasit 150: 4, 283-290.

5. Costa DN, Codeço CT, Silva MA, Werneck GL. 2013. El sacrificio de perros en escenarios de control imperfecto: impacto realista en la prevalencia de la leishmaniasis visceral canina. PLoS Negl Trop Dis 7: 8, e2355.

6. Dacosta MS et al. 2009. Identification of Leishmania sp isolated in human cases in Mato Grosso do Sul, by means of the polymerase chain reaction. Rev Soc Bras Med Trop 42: 3, 303-308.

7. Dawit G, Girma Z, Simenew K. 2013. A review on biology: epidemiology and public health significance of Leishmaniasis. J Bact Parasit 4: 2.
8. Delima H, Guglielmo Z, Rodríguez A, Convit J, Rodriguez N. 2002. Cotton rats (Sigmodon hispidus) and black rats (Rattus Rattus) as possible reservoirs of Leishmania $s p$ in Lara (Venezuela). Mem Inst Oswaldo Cruz 97: 169174.

9. Ezquerra JP. 2001. Las leishmaniasis: de la biología al control. Laboratorios Intervet SA, Salamanca, España, $200 \mathrm{p}$.

10. Feng AI, Chelsea GH. 2013. The secret life of the city rat: a review of the ecology of urban norway and black rats (Rattus norvegicus and Rattus rattus). Yrbans Ecosystems 17: 149-162.

11. Gómez HC et al. 2017. Leishmania infection in bats from a non-endemic region of Leishmaniasis in Brazil. Parasitology 144: 14, 1980-1986.

12. Gould IT et al. 2013. Leishmaniasis visceral en la Argentina. Notificación y situación vectorial (2006-2012). Medicina (Buenos Aires) 73: 104-110.

13. Krayter L et al. 2014. Multilocus microsatellite typing reveals a genetic relation ship but also genetic differences between Indian strains of Leishmania tropica causing cutaneous leishmaniasis and those causing visceral leishmaniasis. Parasites Vectors 7: 123.

14. Marchesin SR, Beguelini MR, Faria KC. 2008. Assessing genetic variability in bat species of Emballonuridae, Phyllostomidae, Vespertilionidae and Molossidae families (Chiroptera) by RFLP-PCR. Genet Mol Res 7: 1164-1178.

15. Medkour $\mathbf{H}$ et al. 2019. Potential animal reservoirs (dogs and bats) of human visceral leishmaniasis due to Leishmania infantum in French Guiana. PLoS Negl Trop Dis 13: 6, e0007456.

16. Montalvo CA, Fraga J, Lianet MC, García M, Fonseca L. 2012. Revisión diagnóstica de la leishmaniasis: observación microscópica del parásito a la detección del ADNLeishmaniasis. Rev Cubana Med Trop 64: 2, 108-131.

17. Oliveira FS, Pirmez C, Piresa MQ, Brazil RP, Pacheco, RS. 2005. PCR-based diagnosis for detection of Leishmania in skin and blood of rodents from an endemic area of cutaneous and visceral leishmaniasis in Brazil. Vet Parasit 129: 219-227.

18. OPS/OMS/PRY. 2018. Manual de diagnóstico y tratamiento de Leishmaniasis. Centro de Inform \& Conocim Minist Salud Pública y Bienestar Social, 92 p.

19. Parhizkari M, Motazedian M, Asqari Q, Mehrabani D. 2011. The PCR-based detection of Leishmania major in Mus musculus and other rodents caught in southern Iran: a guide to sample selection. Ann Trop Med Parasit 105: 4, 319-323.

20. Pennisi MG. 2015. Leishmaniosis de animales de compañía en Europa: una actualización. Vet Parasitol 208: 1-2, $35-47$.

21. Psaroulaki AM et al. 2010. Rats as indicators of the presence and dispersal of six zoonotic microbial agents in Cyprus, an island ecosystem: a seroepidemiological study. Trans R Soc Trop Med Hyg 104: 11, 733-739.

22. Quinnell RJ, Courtenay O. 2009. Transmisión, reservorios y control de leishmaniasis visceral zoonótica. Parasitología 136: 14, 1915-1934. 
23. Reithinger R, Dujardin JC. 2007. Molecular diagnosis of leishmaniasis current status and future applications. JClin Microbiol 45: 21-25.

24. Roque AL, Cupolillo E, Marchevsky RS, Jansen AM. 2010. Thrichomys laurentius (Rodentia; Echimyidae) as a putative reservoir of Leishmania infantum and L. braziliensis: patterns of experimental infection. PLoS Negl Trop Dis 4 : e589.

25. Savani ES et al. 2010. Detection of Leishmania amazonensis and Leishmania infantum chagasi in Brazilian bats. Vet Parasit 168: 5-10.

26. Shapiro JT et al. 2013. First record of Leishmania braziliensis presence detected in bats, Mato Grosso do Sul, southwest Brazil. Acta Tropica 128: 171-174.

27. Svobodova M, Votýpka J, Nicolas L, Volf P. 2003. Leishmania tropica in the black rat (Rattus rattus): persistence and transmission from asymptomatic host to sand fly vector Phlebotomus sergenti. Microbes \& infection 5: 361-364.
28. Tavares TP et al. 2012. Natural infection of Leishmania (Viannia) braziliensis in Mus musculus captures in Mato Grosso, Brazil. Short comunications. Vector-Borne \& Zoon Dis. Vol. 12: 1.

29. Uliana SR, Nelson K, Beberley SM, Camargo EP, Floeter LM. 1994. Discrimination amongs Leishmania by polymerase chain reaction and hibridization with small subunit ribosomal DNA derived oligonucleotides. JEuk. Microb 41: 4, 324.

30. Walker JA et al. 2004. Cuantitative PCR for ADN identification base dan genome-specific interspersed repetitive elements. Genomics 83: 3, 518-527. 